\title{
Gloriosa superba Mediated Synthesis of Platinum and Palladium Nanoparticles for Induction of Apoptosis in Breast Cancer
}

\author{
Shalaka S. Rokade, ${ }^{1}$ Komal A. Joshi, ${ }^{2}$ Ketakee Mahajan, ${ }^{2}$ Saniya Patil, ${ }^{2}$ Geetanjali Tomar, ${ }^{2}$ \\ Dnyanesh S. Dubal, ${ }^{3}$ Vijay Singh Parihar, ${ }^{4}$ Rohini Kitture, ${ }^{5}$ Jayesh R. Bellare, ${ }^{6}$ \\ and Sougata Ghosh ${ }^{7}{ }^{7}$ \\ ${ }^{1}$ Department of Microbiology, Modern College of Arts, Science and Commerce, Ganeshkhind, Pune 411016, India \\ ${ }^{2}$ Institute of Bioinformatics and Biotechnology, Savitribai Phule Pune University, Pune 411007, India \\ ${ }^{3}$ Indian Institute of Science, Education and Research, Pashan, Pune 411008, India \\ ${ }^{4}$ Department of Biomedical Sciences and Engineering, BioMediTech, Tampere University of Technology, \\ Korkeakoulunkatu 10, 33720 Tampere, Finland \\ ${ }^{5}$ Department of Applied Physics, Defense Institute of Advanced Technology, Girinagar, Pune 411025, India \\ ${ }^{6}$ Department of Chemical Engineering, Indian Institute of Technology Bombay, Powai, Mumbai 400076, India \\ ${ }^{7}$ Department of Microbiology, School of Science, RK University, Kasturbadham, Rajkot 360020, India
}

Correspondence should be addressed to Sougata Ghosh; ghoshsibb@gmail.com

Received 27 February 2018; Revised 16 May 2018; Accepted 26 May 2018; Published 2 July 2018

Academic Editor: Konstantinos Tsipis

Copyright (c) 2018 Shalaka S. Rokade et al. This is an open access article distributed under the Creative Commons Attribution License, which permits unrestricted use, distribution, and reproduction in any medium, provided the original work is properly cited.

\begin{abstract}
Green chemistry approaches for designing therapeutically significant nanomedicine have gained considerable attention in the past decade. Herein, we report for the first time on anticancer potential of phytogenic platinum nanoparticles (PtNPs) and palladium nanoparticles (PdNPs) using a medicinal plant Gloriosa superba tuber extract (GSTE). The synthesis of the nanoparticles was completed within 5 hours at $100^{\circ} \mathrm{C}$ which was confirmed by development of dark brown and black colour for PtNPs and PdNPs, respectively, along with enhancement of the peak intensity in the UV-visible spectra. High-resolution transmission electron microscopy (HRTEM) showed that the monodispersed spherical nanoparticles were within a size range below $10 \mathrm{~nm}$. Energy dispersive spectra (EDS) confirmed the elemental composition, while dynamic light scattering (DLS) helped to evaluate the hydrodynamic size of the particles. Anticancer activity against MCF-7 (human breast adenocarcinoma) cell lines was evaluated using MTT assay, flow cytometry, and confocal microscopy. PtNPs and PdNPs showed $49.65 \pm 1.99 \%$ and $36.26 \pm 0.91 \%$ of anticancer activity. Induction of apoptosis was most predominant in the underlying mechanism which was rationalized by externalization of phosphatidyl serine and membrane blebbing. These findings support the efficiency of phytogenic fabrication of nanoscale platinum and palladium drugs for management and therapy against breast cancer.
\end{abstract}

\section{Introduction}

Spectacular development in the field of nanotechnology has led to the fabrication of exotic nanostructures with attractive physicochemical and optoelectronic properties. Nanomaterials have got broad-spectrum therapeutic applications which include carbon-based nanostructures, semiconductor quantum dots, polymeric particles, metallic nanoparticles, and magnetic nanoparticles. However, flexibility to vary the properties like shape, size, composition, assembly, and encapsulation has made metallic nanoparticles most preferred over others for biomedical applications [1]. Platinum-based therapeutic drugs, notably cisplatin and carboplatin, are exploited in chemotherapy against cancer, while platinum nanoparticles (PtNPs) have gained attention only recently [2]. Similarly, palladium nanoparticles (PdNPs) are also reported to exhibit anticancer activity against human leukemia (MOLT-4) cells [3]. Although there are so many 
physical and chemical methods for synthesis of PtNPs and PdNPs, biological methods are considered to be advantageous as they are more biocompatible and less toxic which is a prerequisite for an ideal candidate nanomedicine. Recently, we have shown the potential of medicinal plants like Dioscorea bulbifera, Gnidia glauca, Plumbago zeylanica, Dioscorea oppositifolia, Barleria prionitis, Litchi chinensis, and Platanus orientalis for synthesis of gold, silver, and bimetallic nanoparticles [4-15]. Medicinal plants are storehouses of variety of phytochemicals which may play a vital role in synthesis and stabilization of the bioreduced nanoparticles [16-23]. Hence, it is economical and efficient. Although we have reported its potential for synthesis of gold nanoparticles (AuNPs) and silver nanoparticles (AgNPs) earlier, there are no reports on synthesis of PtNPs and PdNPs till date by Gloriosa superba tuber extract (GSTE) [24]. G. superba is reported to harbour several groups of secondary metabolites such as alkaloids, flavonoids, glycosides, phenols, saponins, steroids, tannins, and terpenoids [25]. The roots are widely used as germicide, to cure ulcers, piles, haemorrhoids, inflammation, scrofula, leprosy, dyspepsia, worm's infestation, flatulence, intermittent fevers, debility, arthritis, and against snake poison [26]. But no extensive studies have been carried out till date on its nanobiotechnological applications.

In view of the background, herein we report synthesis of PtNPs and PdNPs using GSTE which was further characterized using UV-visible spectroscopy, high-resolution transmission electron microscopy (HRTEM), energy dispersive spectroscopy (EDS), dynamic light scattering (DLS), and X-ray diffraction (XRD) analysis. Furthermore, the bioreduced nanoparticles were checked for anticancer activity against MCF-7 cell lines.

\section{Materials and Methods}

2.1. Plant Material and Extract Preparation. GSTE was prepared by collecting G. superba fresh tubers from the Western Ghats of Maharashtra, India, which were thoroughly washed, chopped into small pieces, and shade-dried for 2 days. The dried tubers were reduced to fine powder in an electric blender, $5 \mathrm{~g}$ of which was added to $100 \mathrm{~mL}$ of distilled water in a $300 \mathrm{~mL}$ Erlenmeyer flask and boiled for 5 minutes and eventually collected by decantation followed by filtration through a Whatman number 1 filter paper. The resulting filtrate was used for synthesis of nanoparticles [14].

2.2. Synthesis and UV-Vis Spectroscopy. Reduction of $\mathrm{PtCl}_{6}{ }^{2-}$ ions was initiated by addition of $5 \mathrm{~mL}$ of GSTE to $95 \mathrm{~mL}$ of $10^{-3} \mathrm{M}$ aqueous $\mathrm{H}_{2} \mathrm{PtCl}_{6} \cdot 6 \mathrm{H}_{2} \mathrm{O}$ solution, while for synthesis of PdNPs, $5 \mathrm{~mL}$ of GSTE was mixed with $95 \mathrm{~mL}$ of $10^{-3} \mathrm{M}$ aqueous $\mathrm{PdCl}_{2}$. The resulting mixtures were incubated at $100^{\circ} \mathrm{C}$ for 5 hours with constant stirring for synthesis of PtNPs and PdNPs which was monitored at regular intervals using UV-Vis spectroscopy on a spectrophotometer (SpectraMax M5, Molecular Devices Corp, USA) operated at resolution of $1 \mathrm{~nm}[18,27]$.
2.3. High-Resolution Transmission Electron Microscopy (HRTEM), Energy Dispersive Spectroscopy (EDS), Dynamic Light Scattering (DLS), and X-Ray Diffraction (XRD). Morphological features like size and shape of bioreduced PtNPs and PdNPs were determined using JEOL-JEM-2100 high-resolution transmission electron microscope (HRTEM) equipped with a energy dispersive spectrometer (EDS) at an energy range of $0-20 \mathrm{keV}$. Particle size was analyzed using the dynamic light scattering equipment (Zetasizer Nano-2590, Malvern Instruments Ltd., Worcestershire, UK) in polystyrene cuvette $[14,15]$. The diffraction data for the dry powder were recorded on a Bruker X-ray diffractometer using a Cu K $\alpha(1.54 \AA)$ source [28].

2.4. Fourier-Transform Infrared (FTIR) Spectroscopy. After 5 hours of synthesis of PtNPs and PdNPs using GSTE, the resulting mixture was centrifuged at $10,000 \mathrm{rpm}$ for 15 minutes. The supernatant was collected which was added on $\mathrm{KBr}$ and dried. Similarly, GSTE before bioreduction was also used to compare the alteration of the phytochemistry. The $\mathrm{KBr}$ pellet containing GSTE before and after bioreduction was subjected to FTIR (IRAffinity-1, Shimadzu Corp, Tokyo, Japan) spectroscopy measurement in the diffused reflection mode at a resolution of $4 \mathrm{~cm}^{-1}$ subjected to the IR source $500-4000 \mathrm{~cm}^{-1}[8]$.

2.5. Anticancer Activity. Anticancer activities of PtNPs and PdNPs were compared using MTT (3-(4,5-dimethyl-thiazol2-yl)-2,5-diphenyl-tetrazolium bromide) assay. MCF-7 cells were seeded $\left(4 \times 10^{4}\right.$ cells/well $)$ in a 96-well plate and incubated for adherence for 24 hours, at $37^{\circ} \mathrm{C}$ with $5 \% \mathrm{CO}_{2}$ concentration followed by which nanoparticles were added at a final concentration of $200 \mu \mathrm{g} / \mathrm{mL}$ and incubated for 48 hours. Medium was removed thereafter, and PBS was used to wash the cells. In each well, MTT $(0.5 \mathrm{mg} / \mathrm{mL})$ was added and incubated for 3 hours. The resulting formazan crystals were solubilised in acidified isopropanol, and the absorbance was measured at $570 \mathrm{~nm}$. The statistical analysis was done by using one-way ANOVA.

2.6. Flow Cytometric Analysis. The mechanism underlying the anticancer activity of the PtNPs and PdNPs against MCF-7 cells was studied using flow cytometric analysis of cells treated with respective nanoparticles. $5 \times 10^{5}$ cells were initially seeded in a T-25 flask and incubated for 24 hours followed by addition of PtNPs and PdNPs nanoparticles at a concentration of $200 \mu \mathrm{g} / \mathrm{mL}$. After 48 hours of incubation, the cells were harvested and stained with Annexin V-FITC (dilution $1: 20$ ) and propidium iodide (dilution $1: 20$ ) for 15 minutes at $4^{\circ} \mathrm{C}$ and were acquired using BD FACSVerse and analyzed by BD FACSuit software as reported earlier $[8,14]$.

2.7. Confocal Microscopy. In order to support flow cytometric analysis, immunofluorescence staining was performed to find out the mechanism of cell death in MCF-7 cells on treatment with PtNPs and PdNPs. Cells were seeded at a density of $5 \times 10^{4}$ cells on to glass coverslips followed by 


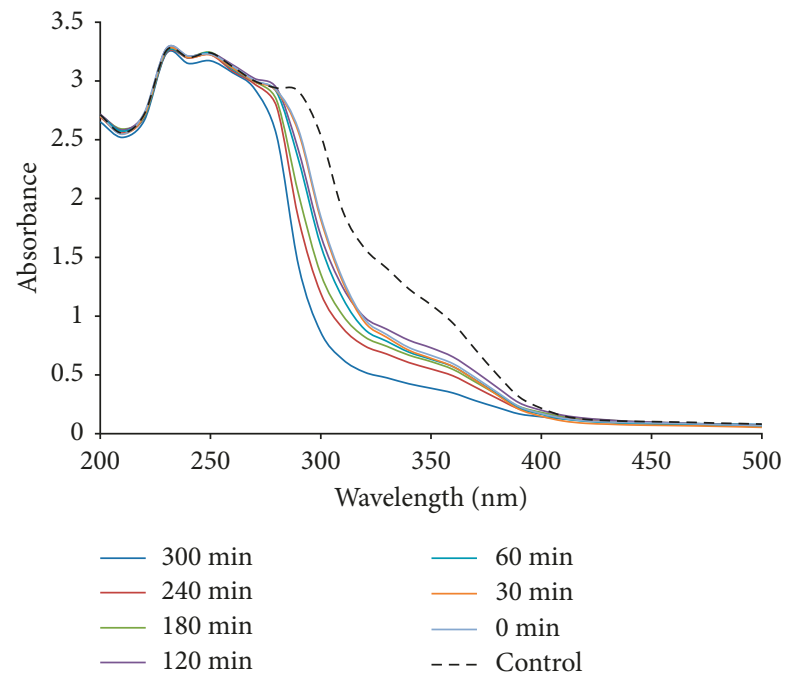

(a)

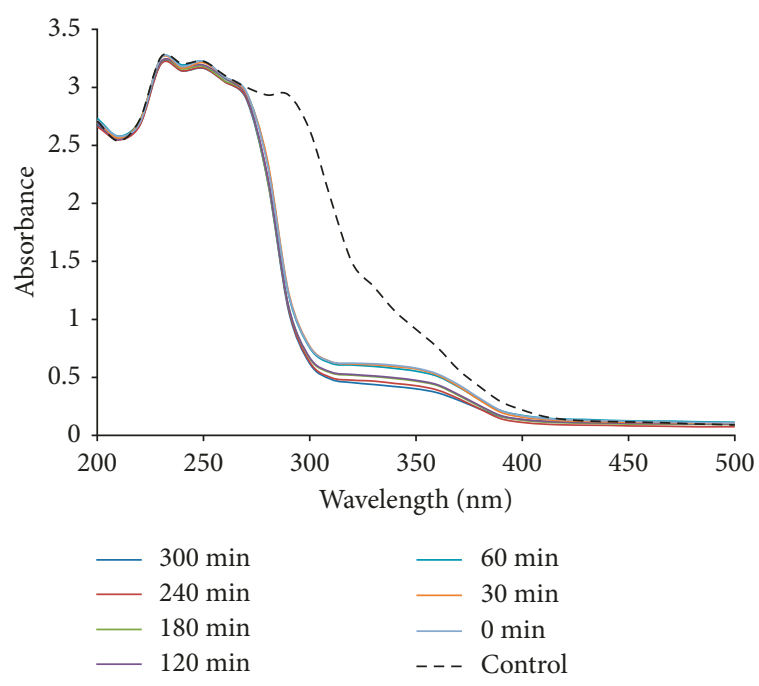

(b)

FIGURE 1: UV-Vis spectra recorded at different time intervals for nanoparticle formation using GSTE at $100^{\circ} \mathrm{C}$ with (a) $1 \mathrm{mM} \mathrm{H}_{2} \mathrm{PtCl}_{6} \cdot 6 \mathrm{H}_{2} \mathrm{O}$ solution and (b) $1 \mathrm{mM} \mathrm{PdCl}$ solution. Control represents corresponding salt solution without GSTE.

incubation for 24 hours for adherence and then treated thereafter with $200 \mu \mathrm{g} / \mathrm{mL}$ of PtNPs and PdNPs for 48 hours. The treated cells were stained with Annexin V(AV)-FITC and PI, both at a dilution of $1: 20$ for 15 minutes at $4^{\circ} \mathrm{C}$ followed by observation under the LSM 780 confocal laser scanning microscope, Carl Zeiss $[8,14,24]$.

\section{Results and Discussion}

3.1. UV-Visible Spectra. GSTE served as source of the phytomolecules which could efficiently synthesize and stabilize PtNPs and PdNPs that were further studied for anticancer activity. Development of brown colour on addition of GSTE in $\mathrm{H}_{2} \mathrm{PtCl}_{6} \cdot 6 \mathrm{H}_{2} \mathrm{O}$ salt solution on incubation at $100^{\circ} \mathrm{C}$ indicated the synthesis of PtNPs. UV-visible spectra showed the decrease in the intensity specific to the $\mathrm{H}_{2} \mathrm{PtCl}_{6} \cdot 6 \mathrm{H}_{2} \mathrm{O}$ salt solution till 5 hours, beyond which no significant decrease was observed which confirmed the completion of the synthesis (Figure 1(a)). Similarly, initially, dark brown colour was developed which eventually turned into black on reaction of GSTE with $\mathrm{PdCl}_{2}$ solution under same conditions. Decrease in the intensity of the UVspectrum corresponding to $\mathrm{PdCl}_{2}$ solution confirmed the synthesis of PdNPs within 5 hours (Figure 1(b)). This result is well in agreement with the previous reports where nanoscale PtNPs and PdNPs were synthesized using medicinal plants like $D$. bulbifera and $B$. prionitis $[8,14]$. The synthesis was found to be faster as compared to synthesis using Glycine max and Cinnamomum camphora, both of which took 48 hours for complete synthesis of PdNPs $[29,30]$. As displayed in Figure 1, the absorption spectra of platinum and palladium colloidal suspensions after 5 hours of bioreduction by GSTE were compared with the absorption spectra of their respective salt solution. Previous reports confirm that the absorption bands appearing in the contrast spectrum of corresponding salt solution were ascribed to the ligand-to-metal charge-transfer transition of the ions. The absence of the absorption peaks above $300 \mathrm{~nm}$ in all the samples after 5 hours indicated complete reduction of the metal ions. Similar accreditation was made during thermally induced reduction of $\mathrm{Pd}(\mathrm{Fod})_{2}$ in o-xylene and sonochemical reduction of $\mathrm{Pd}\left(\mathrm{NO}_{3}\right)_{2}$ in aqueous solution, respectively. Absence of absorption peaks was consistent with the theoretical study of the surface plasmon resonance absorption of PdNPs. The spectra of colloidal suspensions of PtNPs and PdNPs presented broad absorption continua extending throughout the visible-near-ultraviolet region, which were also observed earlier for the platinum group of metals [31-35].

3.2. HRTEM Analysis. Morphological analysis of the assynthesized PtNPs and PdNPs was performed using highresolution transmission electron microscopy (HRTEM). Figures 2(a) and 2(b) reveal the size and shape of the bioreduced PtNPs. The synthesized PtNPs were very small that were majorly of spherical shape, while the diameter was in a range from $0.8 \mathrm{~nm}$ to $3 \mathrm{~nm}$. In the magnified overview of the image, the particles were seen to be embedded in a biological matrix may be derived from the GSTE which can play a critical role in the stabilization process. Diospyros kaki was reported to synthesize PtNPs of larger size, the diameter was found to be in a range between 2 and $12 \mathrm{~nm}$ [36]. At $90^{\circ} \mathrm{C}$, Cacumen platycladi is reported to synthesize very small PtNPs varying in a range of $2.4 \pm 0.8 \mathrm{~nm}[37,38]$. Figures 2(c) and 2(d) showed the morphological characteristics of the PdNPs which were also predominantly spherical in shape, and the diameter of the particles was found to vary in a narrow range between 5 and $8 \mathrm{~nm}$. It is very rare to get such monodispersed uniform nanoparticles using a biological route. Similarly, previous study reports that PdNPs synthesized using Glycine max were found to be 


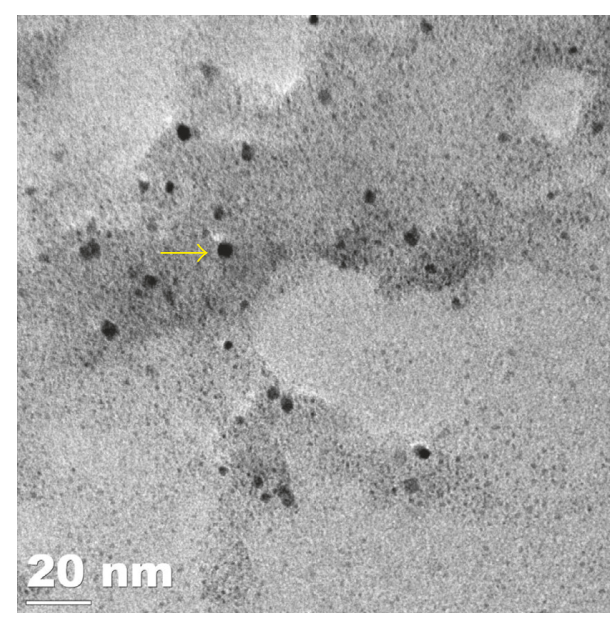

(a)

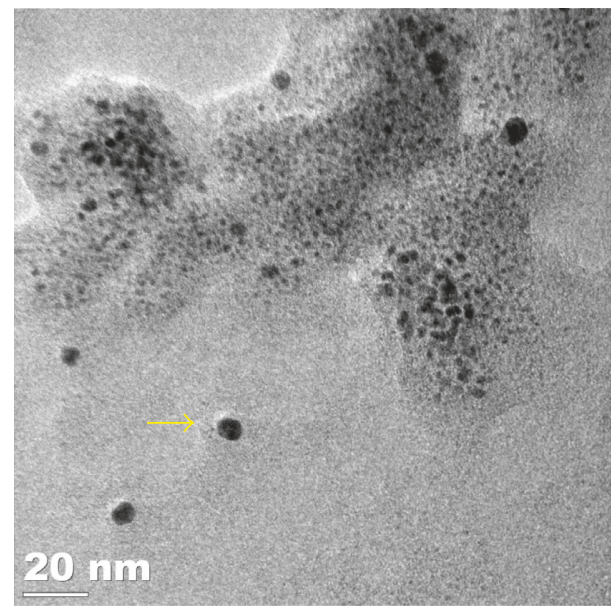

(c)

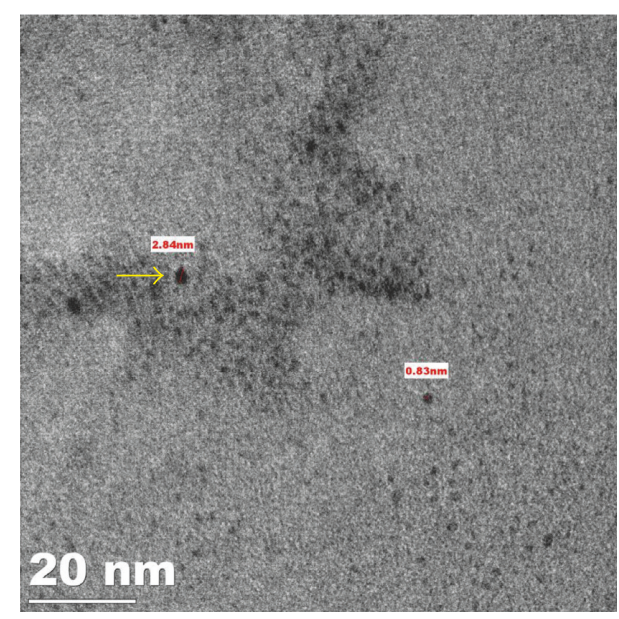

(b)

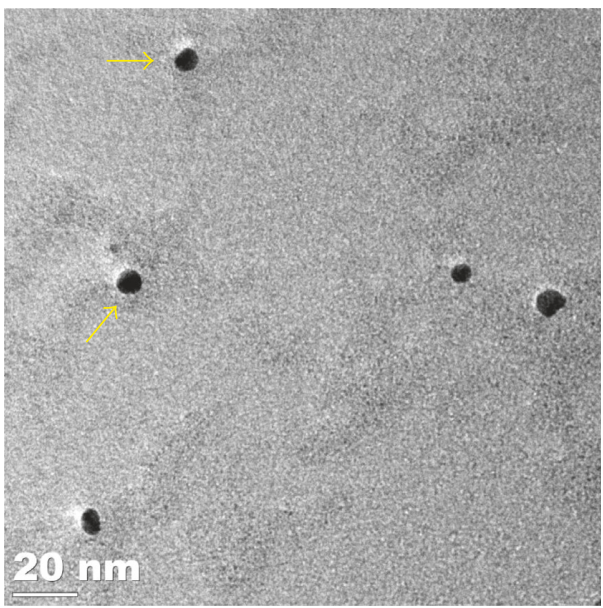

(d)

FIgure 2: HRTEM images of nanoparticles synthesized by GSTE: PtNPs with inset scale bar showing (a) $100 \mathrm{~nm}$ and (b) $20 \mathrm{~nm}$; PdNPs with inset scale bar showing (c) $20 \mathrm{~nm}$ and (d) $20 \mathrm{~nm}$.

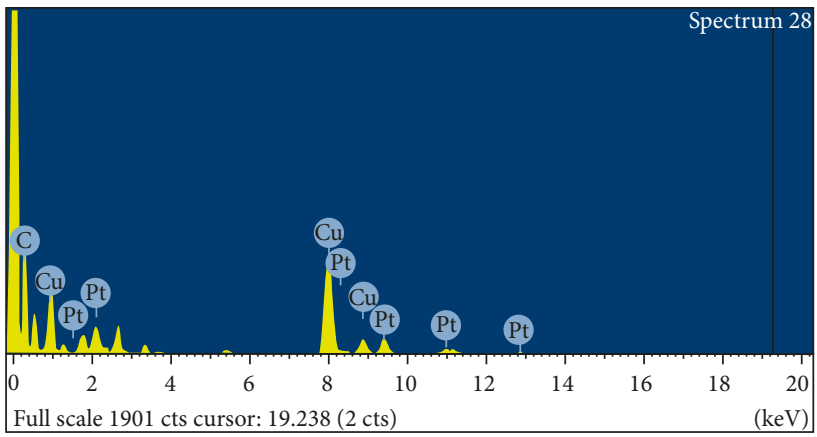

(a)

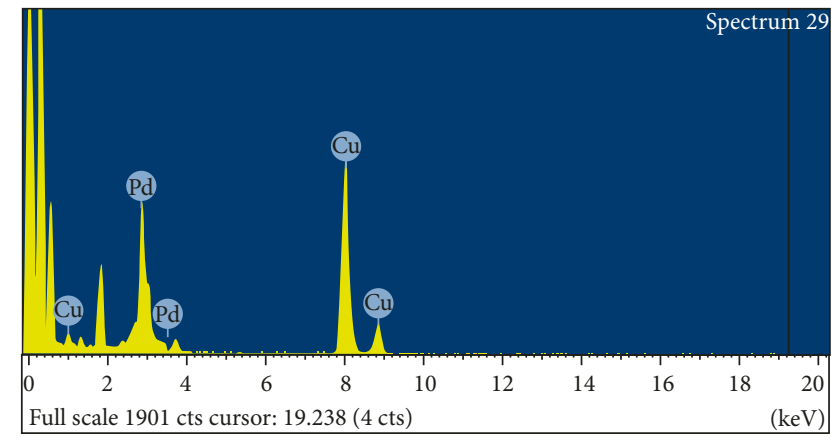

(b)

FIGURE 3: Representative spot EDS of nanoparticles synthesized by GSTE: (a) presence of platinum in PtNPs; (b) presence of palladium in PdNPs.

bigger in size which was $15 \mathrm{~nm}$ in diameter [29]. The energy dispersive spectra profile confirmed the presence of elemental platinum and palladium in PtNPs and PdNPs, respectively (Figure 3). Hydrodynamic size recorded for the bioreduced nanoparticles was also in agreement with the observed HRTEM data. However, larger dimensions were also visualized in DLS spectra which may be due to the nanoparticles trapped in the phytochemical entities from GSTE (Figure 4) [7]. Table 1 gives a comprehensive account of various medicinal plants like Anacardium occidentale, 


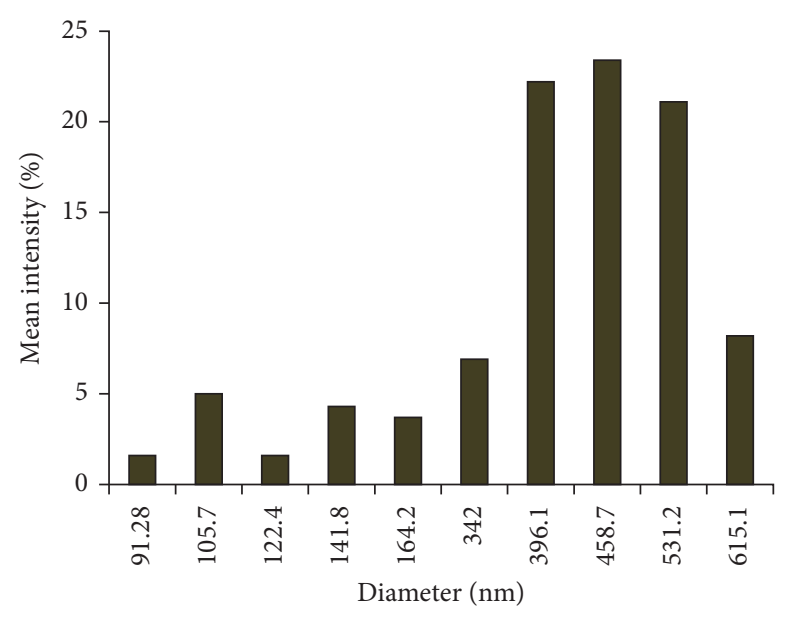

(a)

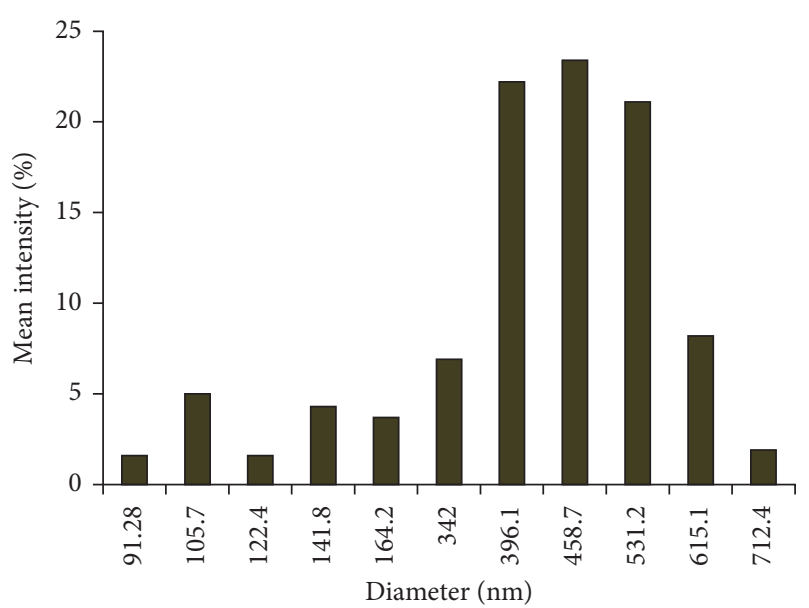

(b)

Figure 4: Dynamic light scattering measurement showing size distribution of nanoparticles synthesized by GSTE: (a) PtNPs; (b) PdNPs.

Table 1: Phytogenic PtNPs and PdNPs.

\begin{tabular}{|c|c|c|c|c|c|c|}
\hline $\begin{array}{l}\text { Serial } \\
\text { number }\end{array}$ & Plant & Extract used & NPs & Shape & $\begin{array}{l}\text { Size } \\
(\mathrm{nm})\end{array}$ & Reference \\
\hline 1 & Cacumen platycladi & $\begin{array}{l}\text { Whole } \\
\text { biomass }\end{array}$ & PtNPs & Spherical & $2.4 \pm 0.8$ & {$[38]$} \\
\hline 2 & Anacardium occidentale & Leaf & PtNPs & Irregular and rod shaped & - & [39] \\
\hline 3 & Diospyros kaki & Leaf & PtNPs & Spheres and plates & $2-20$ & [36] \\
\hline 4 & Ocimum sanctum & Leaf & PtNPs & Irregular & 23 & {$[42]$} \\
\hline 5 & Fumariae herba & Whole herb & PtNPs & Hexagonal and pentagonal & 30 & {$[43]$} \\
\hline 6 & Curcuma longa & Tuber & PdNPs & Spherical & $15-20$ & {$[44]$} \\
\hline 7 & Gardenia jasminoides Ellis & Fruit & PdNPs & $\begin{array}{c}\text { Spherical, rod, and three-dimensional } \\
\text { polyhedra }\end{array}$ & $3-5$ & [45] \\
\hline 8 & Glycine max & Leaf & PdNPs & Spherical & 15 & [29] \\
\hline 9 & Punica granatum & Peel & PtNPs & Spherical & $16-23$ & {$[46]$} \\
\hline 10 & Cinnamomum camphora & Leaf & PdNPs & Irregular & 6 & {$[30]$} \\
\hline 11 & Annona squamosa $\mathrm{L}$. & Peel & PdNPs & Spherical & 100 & [41] \\
\hline 12 & Pulicaria glutinosa & Whole plant & PdNPs & Spherical & $20-25$ & {$[46,47]$} \\
\hline 13 & Delonix regia & Leaf & PdNPs & Spherical & $2-4$ & [48] \\
\hline 14 & Piper betle L. & Leaf & $\begin{array}{l}\text { PtNPs } \\
\text { PdNPs }\end{array}$ & $\begin{array}{l}\text { Spherical } \\
\text { Spherical }\end{array}$ & $\begin{array}{l}2.1 \pm 0.4 \\
3.8 \pm 0.2\end{array}$ & {$[40]$} \\
\hline 15 & Dioscorea bulbifera & Tuber & $\begin{array}{l}\text { PtNPs } \\
\text { PdNPs }\end{array}$ & $\begin{array}{c}\text { Spherical } \\
\text { Spherical and blunt ended cubes }\end{array}$ & $\begin{array}{c}2-5 \\
10-25\end{array}$ & {$[8]$} \\
\hline 16 & Barleria prionitis & Leaf & $\begin{array}{l}\text { PtNPs } \\
\text { PdNPs }\end{array}$ & $\begin{array}{l}\text { Spherical } \\
\text { Spherical and irregular }\end{array}$ & $1-2$ & {$[14]$} \\
\hline
\end{tabular}

Piper betle, Annona squamosa, Terminalia chebula, and Pulicaria glutinosa, which are reported to synthesize either PtNPs, PdNPs, or both [37, 39-41].

3.3. X-Ray Diffraction (XRD) Analysis. The as-synthesized nanoparticles were characterized for their phase with the help of XRD. The powder diffraction data of the dried powder was recorded on a Bruker X-ray diffractometer with $\mathrm{Cu} \mathrm{K} \alpha(1.54 \AA)$ source. Figure 5 shows the XRD data of the PtNPs and PdNPs. The sharp peaks in case of PtNPs and PdNPs represent the crystalline nature of both the nanoparticles. The phase formation has also been confirmed from the data [8]. The characteristic peaks, as seen in Figure 5, correspond to the lattice planes (111), (200), and (220) in case of PtNPs; however, (111) plane was not seen in case of PdNPs. The reason for absence (or no growth) of the (111) plane in case of PdNPs needs to be explored, but at the preliminary stage, we feel that the plant extract might have some crucial role in such restricted growth.

3.4. FTIR Analysis. FTIR spectral analysis showed various functional groups in GSTE before bioreduction and their alteration after synthesis of PtNPs and PdNPs (Figure 6). GSTE showed a prominent peak of the hydroxyl group specific to alcoholic and phenolic compounds at $\sim 3300 \mathrm{~cm}^{-1}$, which remain unaltered even after nanoparticles synthesis. 


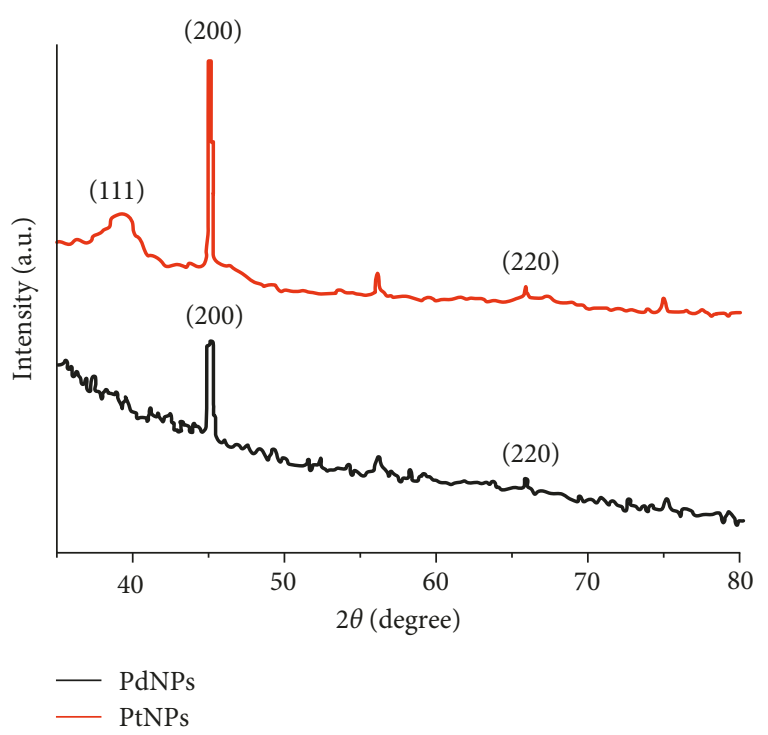

Figure 5: Representative X-ray diffraction profile of thin film PtNPs and PdNPs, synthesized by GSTE.

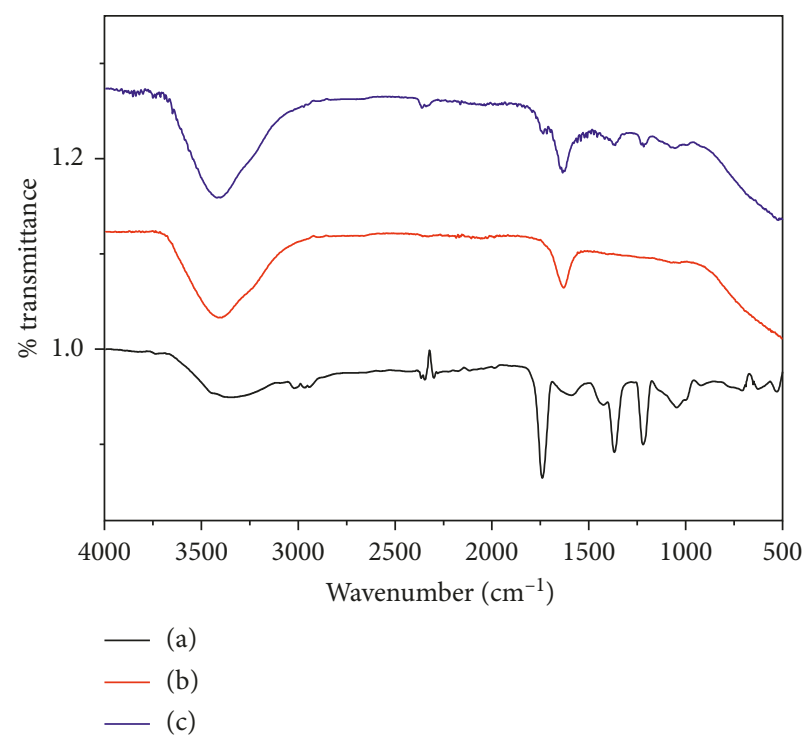

FIGURE 6: FTIR spectra of GSTE. (a) Before synthesis of nanoparticles, (b) after synthesis of PtNPs, and (c) after synthesis of PdNPs.

Similarly, peaks observed at 1049, 1218, 1369, and $1737 \mathrm{~cm}^{-1}$ can be attributed to the $\mathrm{C}-\mathrm{O}-\mathrm{C}$ bond in ether, unassigned amide mode, $\mathrm{CH}_{3}$ bend, and stretching of $\mathrm{C}=\mathrm{O}$ bond, respectively, which disappeared after synthesis of nanoparticles. This indicates that phytochemicals with abovementioned functional groups are responsible for reduction of the metal ions salts leading to synthesis of corresponding nanoparticles. However, a significant feature of the amide bond at $1627 \mathrm{~cm}^{-1}$ seen in GSTE is recovered after synthesis, suggesting the replacement of carboxylic group by amines, which in turn again supports the hypothesis of role of carboxylic and similar groups in reduction of the metal salts into the corresponding metal nanoparticles [49].

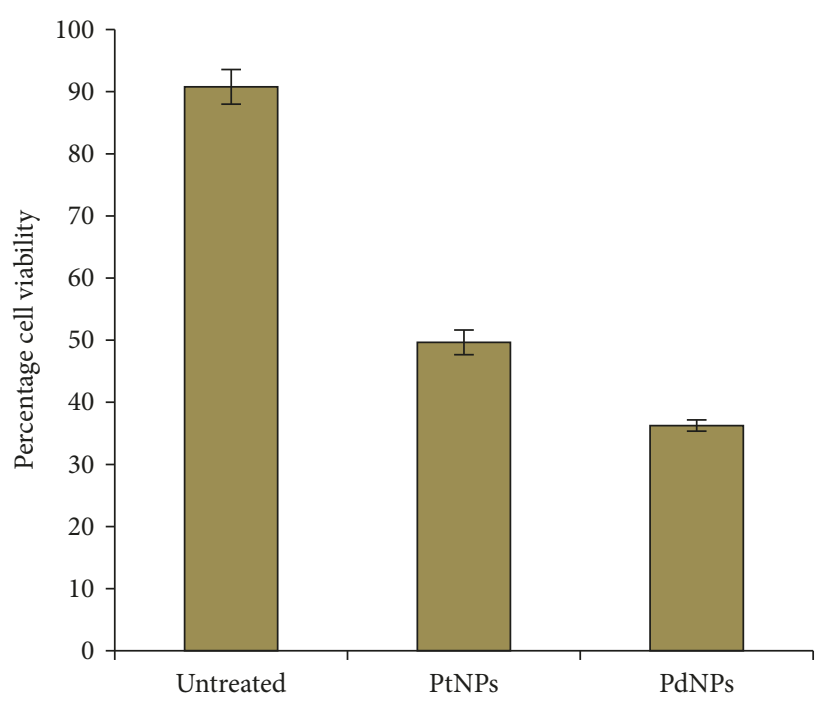

FIgURE 7: Anticancer activity against MCF-7 cells using MTT reduction assay. The data are indicated as the mean $\pm \operatorname{SEM}(n=5)$.

3.5. Anticancer Activity. Apoptosis is considered as programmed cell death orchestrated by cascade of interdependent synchronised cellular events. It is the most critical process for maintenance of homeostasis, where an efficient balance between cell proliferation and cell death is maintained [50]. Fabrication of apoptotic nanoinducers is of prime importance to develop novel nanomedicine against cancer. Platinum drugs like cisplatin, oxaliplatin, and carboplatin are considered as candidates for treatment and management of cancer, although they pose a threat of potential adverse effects. However, there are very less studies on the anticancer activity of biologically synthesized PtNPs and PdNPs. In our study, both PtNPs and PdNPs showed superior anticancer activity by reducing the viability of MCF-7 cells on treatment till 48 hours. PtNPs showed an anticancer activity up to $49.65 \pm 1.99 \%$, while PdNPs showed an activity up to $36.26 \pm 0.91 \%$ (Figure 7 ). PtNPs and PdNPs are reported to exhibit high cytotoxicity owing to their physicochemical interactions with the functional groups of cellular proteins, nitrogen bases, and phosphate groups of the DNA leading to cell death. Earlier reports confirm that Pd leads to formation of free radicals, leakage of lactate dehydrogenase, and cell-cycle disturbances which can be the key underlying mechanism behind the anticancer activity [3]. Cellular deaths are mainly due to either apoptosis, autophagy, or necrosis. In order to determine the percentage of apoptotic and necrotic cells, MCF-7 cells were treated with $200 \mu \mathrm{g} / \mathrm{mL}$ of both PtNPs and PdNPs for 48 hours and stained with Annexin V and PI followed by flow cytometric analysis (Figure 8). Both PtNPs and PdNPs were capable of inducing apoptosis in MCF-7 cells up to $12.32 \%$ and $31.3 \%$, respectively, which was found to be higher compared to previous reports on human lung adenocarcinoma (A549), ovarian teratocarcinoma (PA-1), pancreatic cancer (Mia-PaCa-2) cells, and normal peripheral blood mononucleocyte (PBMC) cells [2]. Our results were comparable to anticancer activity of PdNPs synthesized using Camellia sinensis against 


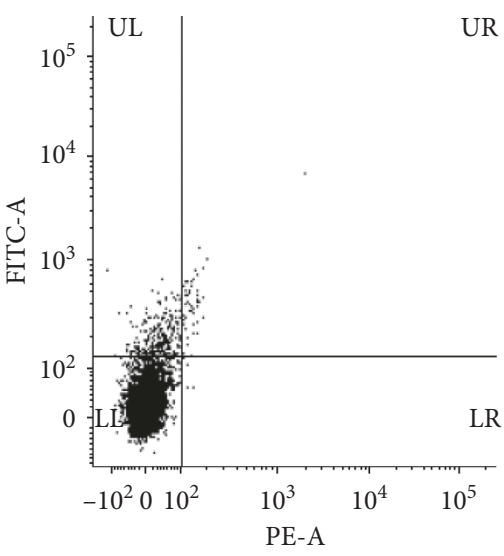

(a)

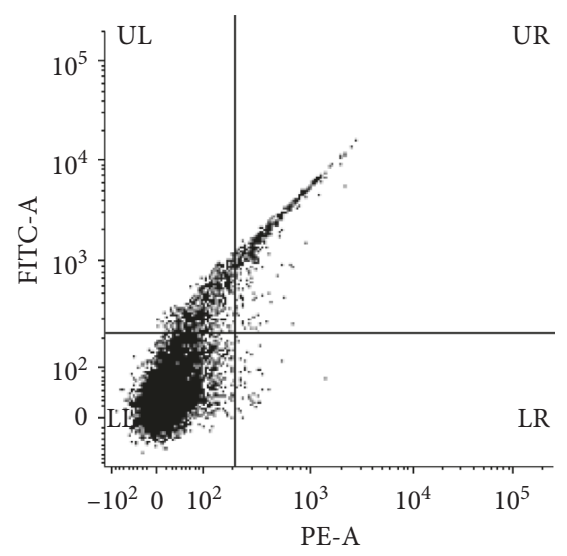

(b)

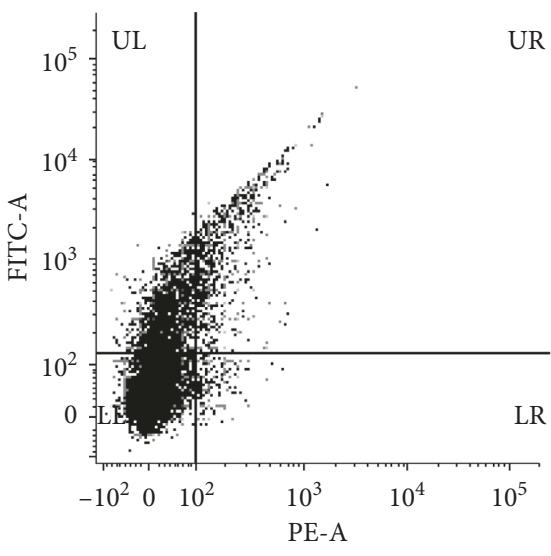

(c)

Figure 8: Flow cytometric analysis for MCF-7 cells treated with PtNPs and PdNPs for 48 hours confirming phosphatidyl serine externalization (Annexin V-FITC binding) and cell membrane disintegration (PI staining) The dual parametric dot plots combining Annexin V-FITC and PI fluorescence show the viable cell population (lower left quadrant, Annexin V-FITC ${ }^{-} \mathrm{PI}^{-}$), the early apoptotic cells (lower

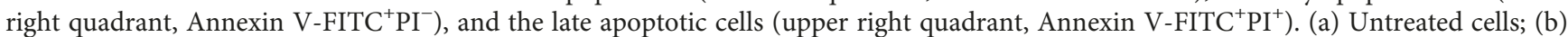
treatment with PtNPs; (c) treatment with PdNPs.

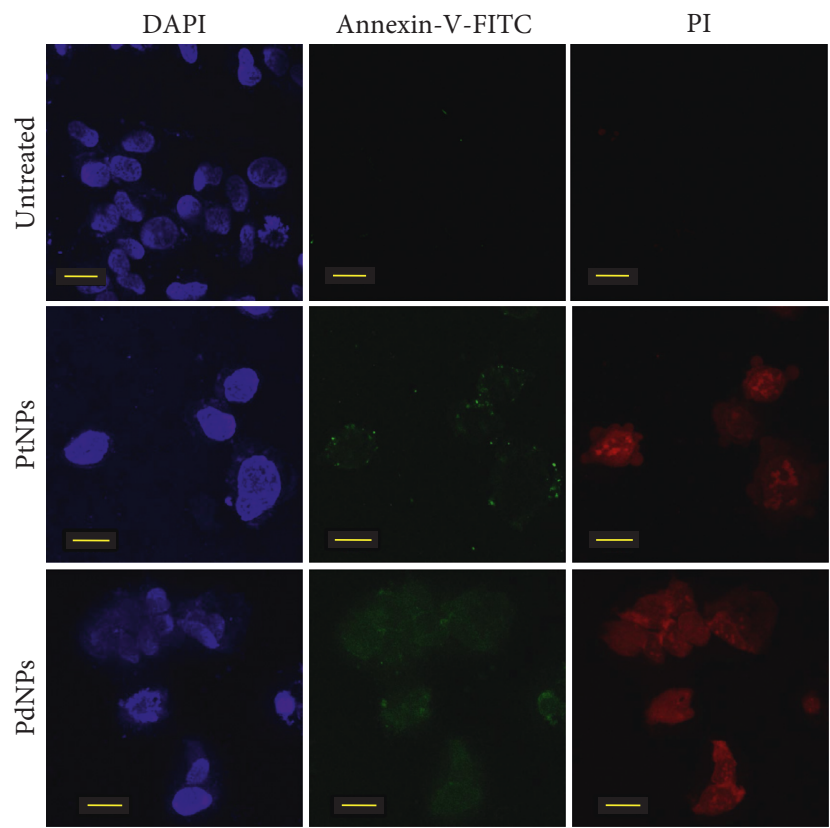

Figure 9: Confocal imaging of apoptosis induction by PtNPs and PdNPs in MCF-7 cells seeded on coverslips and stained with Annexin V-FITC and PI.

human leukemia (MOLT-4) [3]. Recently, such unconventional platinum anticancer agents and associated nanomedicines have got more attention as clinically successful platinum drugs like cisplatin, carboplatin, and oxaliplatin have exhibited tremendous deleterious side effects that include nephrotoxicity, fatigue, emesis, alopecia, ototoxicity, peripheral neuropathy, and myelosupression $[51,52]$. Confocal images also confirmed the induction of apoptosis (Figure 9). Externalization of phosphatidyl serine and membrane disintegration was evident from Annexin V-FITC ${ }^{+} \mathrm{PI}^{+}$MCF-7 cells. Similarly, membrane blebbing and chromosome condensation were also observed in PtNPs treated cells, which is a critical hallmark of apoptosis [8].

\section{Conclusion}

Monodispersed PtNPs and PdNPs were synthesized using G. superba tuber extract which were found to be uniformly spherical and almost isodiametric. The synthesis was found to be rapid, efficient, and environmentally benign. Both PtNPs and PdNPs showed potent anticancer activity against MCF-7 (human breast adenocarcinoma) cells. The mechanism of cell death was confirmed to be induction of apoptosis characterized by phosphatidyl serine externalization, membrane disintegration, and blebbing with chromosome condensation. Further studies on these phytogenic nanoparticles might help to establish their potential as candidate drugs against breast cancer.

\section{Data Availability}

The data used to support the findings of this study are available from the corresponding author upon request.

\section{Conflicts of Interest}

The authors declare that there are no conflicts of interest regarding the publication of this paper.

\section{Acknowledgments}

The authors acknowledge the help extended for the use of TEM and HRTEM facilities in Chemical Engineering and CRNTS funded by the DST through Nanomission and IRPHA schemes. Dr. Geetanjali Tomar thanks DST INSPIRE for the faculty position and the research grants (nos. IFA13 LSBM73 and GOI-E-161(2), resp.). 


\section{References}

[1] D. G. Sant, T. R. Gujarathi, S. R. Harne et al., "Adiantum philippense L. frond assisted rapid green synthesis of gold and silver nanoparticles," Journal of Nanoparticles, vol. 2013, Article ID 182320, 9 pages, 2013.

[2] Y. Bendale, V. Bendale, and S. Paul, "Evaluation of cytotoxic activity of platinum nanoparticles against normal and cancer cells and its anticancer potential through induction of apoptosis," Integrative Medicine Research, vol. 6, no. 2, pp. 141148, 2017.

[3] S. Azizi, M. M. Shahri, H. S. Rahman, R. A. Rahim, A. Rasedee, and R. Mohamad, "Green synthesis palladium nanoparticles mediated by white tea (Camellia sinensis) extract with antioxidant, antibacterial, and antiproliferative activities toward the human leukemia (MOLT-4) cell line," International Journal of Nanomedicine, vol. 12, pp. 8841-8853, 2017.

[4] S. Ghosh, S. Patil, M. Ahire et al., "Synthesis of silver nanoparticles using Dioscorea bulbifera tuber extract and evaluation of its synergistic potential in combination with antimicrobial agents," International Journal of Nanomedicine, vol. 7, pp. 483-496, 2012.

[5] A. K. Mittal, Y. Chisti, and U. C. Banerjee, "Synthesis of metallic nanoparticles using plant extracts," Biotechnology Advances, vol. 31, no. 2, pp. 346-356, 2013.

[6] M. R. Bindhu and M. Umadevi, "Synthesis of monodispersed silver nanoparticles using Hibiscus cannabinus leaf extract and its antimicrobial activity," Spectrochimica Acta Part A: Molecular and Biomolecular Spectroscopy, vol. 101, pp. 184-190, 2013.

[7] A. Schröfel, G. Kratošová, I. Šafařík, M. Šafaříková, I. Raška, and L. M. Shor, "Applications of biosynthesized metallic nanoparticles-a review," Acta Biomaterialia, vol. 10, no. 10, pp. 4023-4042, 2014.

[8] S. Ghosh, R. Nitnavare, A. Dewle et al., "Novel platinumpalladium bimetallic nanoparticles synthesized by Dioscorea bulbifera: anticancer and antioxidant activities," International Journal of Nanomedicine, vol. 10, no. 1, pp. 7477-7490, 2015.

[9] M. Prathap, A. Alagesan, and B. D. R. Kumari, "Anti-bacterial activities of silver nanoparticles synthesized from plant leaf extract of Abutilon indicum (L.) Sweet," Journal of Nanostructure in Chemistry, vol. 4, p. 106, 2014.

[10] R. Majumdar, B. G. Bag, and N. Maity, "Acacia nilotica (Babool) leaf extract mediated size-controlled rapid synthesis of gold nanoparticles and study of its catalytic activity," International Nano Letters, vol. 3, p. 53, 2013.

[11] C. Krishnaraj, R. Ramachandran, K. Mohan, and P. T. Kalaichelvan, "Optimization for rapid synthesis of silver nanoparticles and its effect on phytopathogenic fungi," Spectrochimica Acta Part A: Molecular and Biomolecular Spectroscopy, vol. 93, pp. 95-99, 2012.

[12] J. K. Andeani, H. Kazemi, S. Mohsenzadeh, and A. Safavi, "Biosynthesis of gold nanoparticles using dried flowers extract of Achillea wilhelmsii plant," Digest Journal of Nanomaterials and Biostructures, vol. 6, no. 3, pp. 1011-1017, 2011.

[13] G. R. Salunke, S. Ghosh, R. J. S. Kumar et al., "Rapid efficient synthesis and characterization of AgNPs, AuNPs and AgAuNPs from a medicinal plant Plumbago zeylanica and their application in biofilm control," International Journal of Nanomedicine, vol. 9, no. 1, pp. 2635-2653, 2014.

[14] S. S. Rokade, K. A. Joshi, K. Mahajan et al., "Novel anticancer platinum and palladium nanoparticles from Barleria prionitis," Global Journal of Nanomedicine, vol. 2, no. 5, article 555600, 2017.
[15] S. Shende, K. A. Joshi, A. S. Kulkarni et al., "Litchi chinensis peel: a novel source for synthesis of gold and silver nanocatalysts," Global Journal of Nanomedicine, vol. 3, no. 1, article 555603, 2017.

[16] R. Kitture, S. Ghosh, P. Kulkarni et al., " $\mathrm{Fe}_{3} \mathrm{O}_{4}$-citrate curcumin: promising conjugates for superoxide scavenging, tumor suppression and cancer hyperthermia," Journal of Applied Physics, vol. 111, no. 6, article 064702, 2012.

[17] J. L. Gardea-Torresdey, E. Gomez, J. R. Peralta-Videa, J. G. Parsons, H. Troiani, and M. Jose-Yacaman, "Alfalfa sprouts: a natural source for the synthesis of silver nanoparticles," Langmuir, vol. 19, no. 4, pp. 1357-1361, 2003.

[18] J. L. Gardea-Torresdey, J. G. Parsons, E. Gomez et al., "Formation and growth of Au nanoparticles inside live Alfalfa plants," Nano Letters, vol. 2, no. 4, pp. 397-401, 2002.

[19] R. Rajan, K. Chandran, S. L. Harper, S. I. Yun, and P. Thangavel Kalaichelvan, "Plant extract synthesized silver nanoparticles: an ongoing source of novel biocompatible materials," Industrial Crops and Products, vol. 70, pp. 356373, 2015.

[20] K. S. Kavitha, S. Baker, D. Rakshith et al., "Plants as green source towards synthesis of nanoparticles," International Research Journal of Biological Sciences, vol. 2, no. 6, pp. 66-76, 2013.

[21] M. Khan, M. Khan, S. F. Adil et al., "Green synthesis of silver nanoparticles mediated by Pulicaria glutinosa extract," International Journal of Nanomedicine, vol. 8, no. 1, pp. 15071516, 2013.

[22] P. Kuppusamy, M. M. Yusoff, G. P. Maniam, and N. Govindan, "Biosynthesis of metallic nanoparticles using plant derivatives and their new avenues in pharmacological applications-an updated report," Saudi Pharmaceutical Journal, vol. 24, no. 4, pp. 473-484, 2016.

[23] S. Arokiyaraj, M. V. Arasu, S. Vincent et al., "Rapid green synthesis of silver nanoparticles from Chrysanthemum indicum $\mathrm{L}$ and its antibacterial and cytotoxic effects: an in vitro study," International Journal of Nanomedicine, vol. 9, no. 1, pp. 379-388, 2014.

[24] K. Jyoti, M. Baunthiyal, and A. Singh, "Characterization of silver nanoparticles synthesized using Urtica dioica Linn. leaves and their synergistic effects with antibiotics," Journal of Radiation Research and Applied Sciences, vol. 9, no. 3, pp. 217-227, 2016.

[25] M. Senthilkumar, "Phytochemical screening of Gloriosa superba L. from different geographical positions," International Journal of Scientific and Research Publications, vol. 3, pp. 1-5, 2013.

[26] K. J. R. Gopi and R. Panneerselvam, "Quantification of colchicine in seed and tuber samples of Gloriosa superba by high performance liquid chromatography method," Journal of Applied Pharmaceutical Science, vol. 1, no. 7, pp. 116-119, 2011.

[27] S. S. Shankar, A. Rai, B. Ankamwar, A. Singh, A. Ahmad, and M. Sastry, "Biological synthesis of triangular gold nanoprisms," Nature Materials, vol. 3, no. 7, pp. 482-488, 2004.

[28] S. S. Shankar, A. Rai, A. Ahmad, and M. Sastry, "Controlling the optical properties of lemongrass extract synthesized gold nanotriangles and potential application in infrared-absorbing optical coatings," Chemistry of Materials, vol. 17, no. 3, pp. 566-572, 2005.

[29] R. K. Petla, S. Vivekanandhan, M. Misra, A. K. Mohanty, and N. Satyanarayana, "Soybean (Glycine max) leaf extract based green synthesis of palladium nanoparticles," Journal of Biomaterials and Nanobiotechnology, vol. 3, no. 1, pp. 14-19, 2012. 
[30] X. Yang, Q. Li, H. Wang et al., "Green synthesis of palladium nanoparticles using broth of Cinnamomum camphora leaf," Journal of Nanoparticle Research, vol. 12, no. 5, pp. 1589-1598, 2010.

[31] T. Teranishi and M. Miyake, "Size control of palladium nanoparticles and their crystal structures," Chemistry of Materials, vol. 10, no. 2, pp. 594-600, 1998.

[32] T. Yonezawa, K. Imamura, and N. Kimizuka, "Direct preparation and size control of palladium nanoparticle hydrosols by water-soluble isocyanide ligands," Langmuir, vol. 17, no. 16, pp. 4701-4703, 2001.

[33] C. Luo, Y. Zhang, and Y. Wang, "Palladium nanoparticles in poly(ethyleneglycol): the efficient and recyclable catalyst for Heck reaction," Journal of Molecular Catalysis A: Chemical, vol. 229, no. 1-2, pp. 7-12, 2005.

[34] P. F. Ho and K. M. Chi, "Size-controlled synthesis of Pd nanoparticles from $\beta$-diketonato complexes of palladium," Nanotechnology, vol. 15, no. 8, pp. 1059-1064, 2004.

[35] A. Nemamcha, J. Rehspringer, and D. Khatmi, "Synthesis of palladium nanoparticles by sonochemical reduction of palladium(II) nitrate in aqueous solution," Journal of Physical Chemistry B, vol. 110, no. 1, pp. 383-387, 2006.

[36] J. Y. Song, E. Y. Kwon, and B. S. Kim, "Biological synthesis of platinum nanoparticles using Diopyros kaki leaf extract," Bioprocess and Biosystems Engineering, vol. 33, no. 1, pp. 159-164, 2010.

[37] S. F. Adil, M. E. Assal, M. Khan, A. Al-Warthan, M. R. H. Siddiqui, and L. M. Liz-Marzán, "Biogenic synthesis of metallic nanoparticles and prospects toward green chemistry," Dalton Transactions, vol. 44, no. 21, pp. 97099717, 2015.

[38] B. Zheng, T. Kong, X. Jing et al., "Plant-mediated synthesis of platinum nanoparticles and its bioreductive mechanism," Journal of Colloid and Interface Science, vol. 396, pp. 138-145, 2013.

[39] D. S. Sheny, D. Philip, and J. Mathew, "Synthesis of platinum nanoparticles using dried Anacardium occidentale leaf and its catalytic and thermal applications," Spectrochimica Acta Part A: Molecular and Biomolecular Spectroscopy, vol. 114, pp. 267-271, 2013.

[40] P. Rajasekharreddy and P. U. Rani, "Biosynthesis and characterization of Pd and Pt nanoparticles using Piper betle L. plant in a photoreduction method," Journal of Cluster Science, vol. 25, no. 5, pp. 1377-1388, 2014.

[41] S. M. Roopan, A. Bharathi, R. Kumar, V. G. Khanna, and A. Prabhakarn, "Acaricidal, insecticidal, and larvicidal efficacy of aqueous extract of Annona squamosa L peel as biomaterial for the reduction of palladium salts into nanoparticles," Colloids and Surfaces B: Biointerfaces, vol. 92, pp. 209-212, 2012.

[42] C. Soundarrajan, A. Sankari, P. Dhandapani et al., "Rapid biological synthesis of platinum nanoparticles using Ocimum sanctum for water electrolysis applications," Bioprocess Biosystem Engineering, vol. 35, no. 5, pp. 827-833, 2012.

[43] R. Dobrucka, "Synthesis and structural characteristic of platinum nanoparticles using herbal bidens tripartitus extract," Journal of Inorganic and Organometallic Polymers and Materials, vol. 26, no. 1, pp. 219-225, 2015.

[44] M. Sathishkumar, K. Sneha, and Y. S. Yun, "Palladium nanocrystal synthesis using Curcuma longa tuber extract," International Journal of Materials Sciences, vol. 4, no. 1, pp. 11-17, 2009.

[45] L. Jia, Q. Zhang, Q. Li, and H. Song, "The biosynthesis of palladium nanoparticles by antioxidants in Gardenia jasminoides
Ellis: long life time nanocatalysts for $p$-nitrotoluene hydrogenation," Nanotechnology, vol. 20, no. 38, article 385601, 2009.

[46] P. Dauthal and M. Mukhopadhyay, "Biofabrication, characterization, and possible bio-reduction mechanism of platinum nanoparticles mediated by agro-industrial waste and their catalytic activity," Journal of Industrial and Engineering Chemistry, vol. 22, pp. 185-191, 2015.

[47] M. Khan, M. Khan, M. Kuniyil et al., "Biogenic synthesis of palladium nanoparticles using Pulicaria glutinosa extract and their catalytic activity towards the Suzuki coupling reaction," Dalton Transactions, vol. 43, no. 24, pp. 9026-9031, 2014.

[48] P. Dauthal and M. Mukhopadhyay, "Biosynthesis of palladium nanoparticles using Delonix regia leaf extract and its catalytic activity for nitro-aromatics hydrogenation," Industrial and Engineering Chemistry Research, vol. 52, no. 51, pp. 18131-18139, 2013.

[49] G. Socrates, Infrared and Raman Characteristic Group Frequencies, John Wiley \& Sons, Hoboken, NJ, USA, 3rd edition, 2001.

[50] M. Khan, M. Khan, A. H. Al-Marri et al., "Apoptosis inducing ability of silver decorated highly reduced graphene oxide nanocomposites in A549 lung cancer," International Journal of Nanomedicine, vol. 11, pp. 873-883, 2016.

[51] T. C. Johnstone, G. Y. Park, and S. J. Lippard, "Understanding and improving platinum anticancer drugs-phenanthriplatin," Anticancer Research, vol. 34, no. 1, pp. 471-476, 2014.

[52] I. DeAlba-Montero, J. Guajardo-Pacheco, E. Morales-Sánchez et al., "Antimicrobial properties of copper nanoparticles and amino acid chelated copper nanoparticles produced by using a soya extract," Bioinorganic Chemistry and Applications, vol. 2017, Article ID 1064918, 6 pages, 2017. 

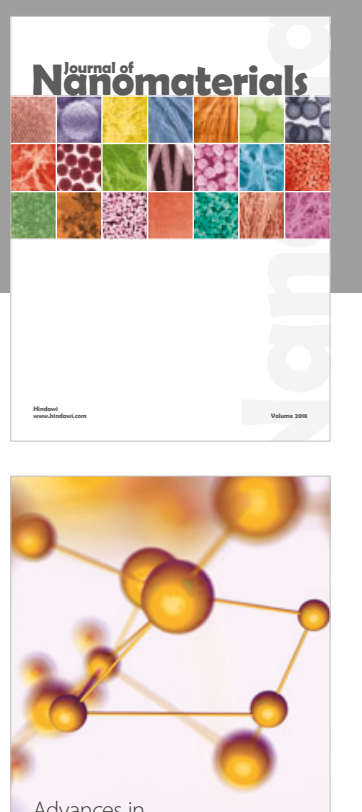

Physical Chemistry
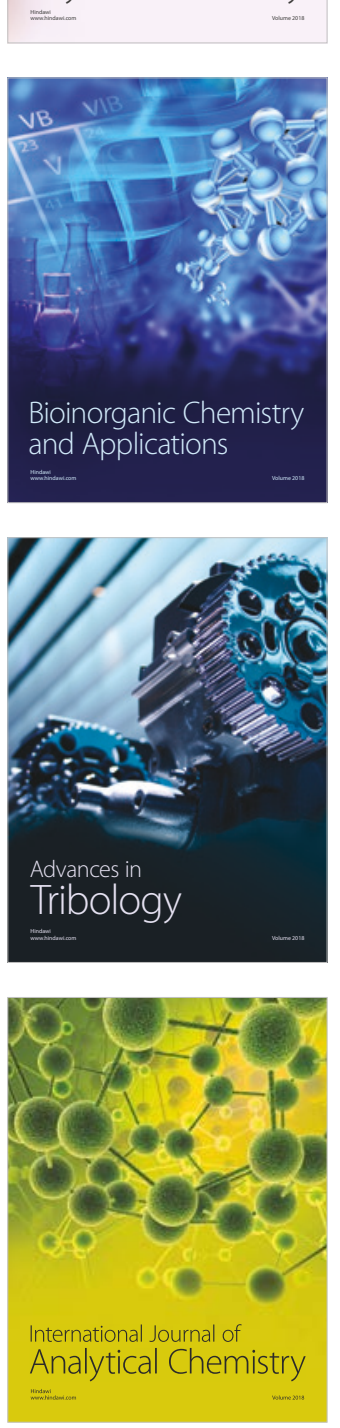

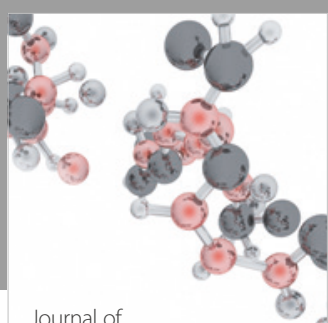

Analytical Methods

in Chemistry

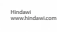

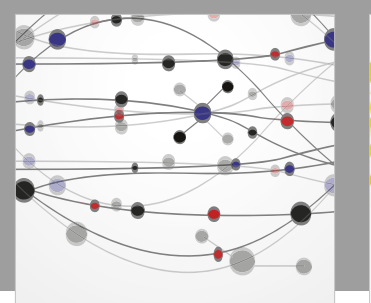

The Scientific World Journal

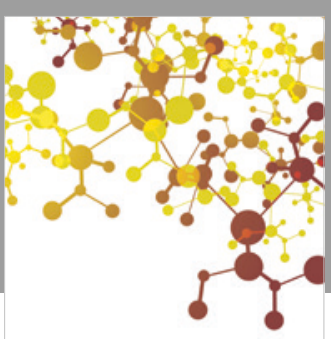

Journal of

Applied Chemistry
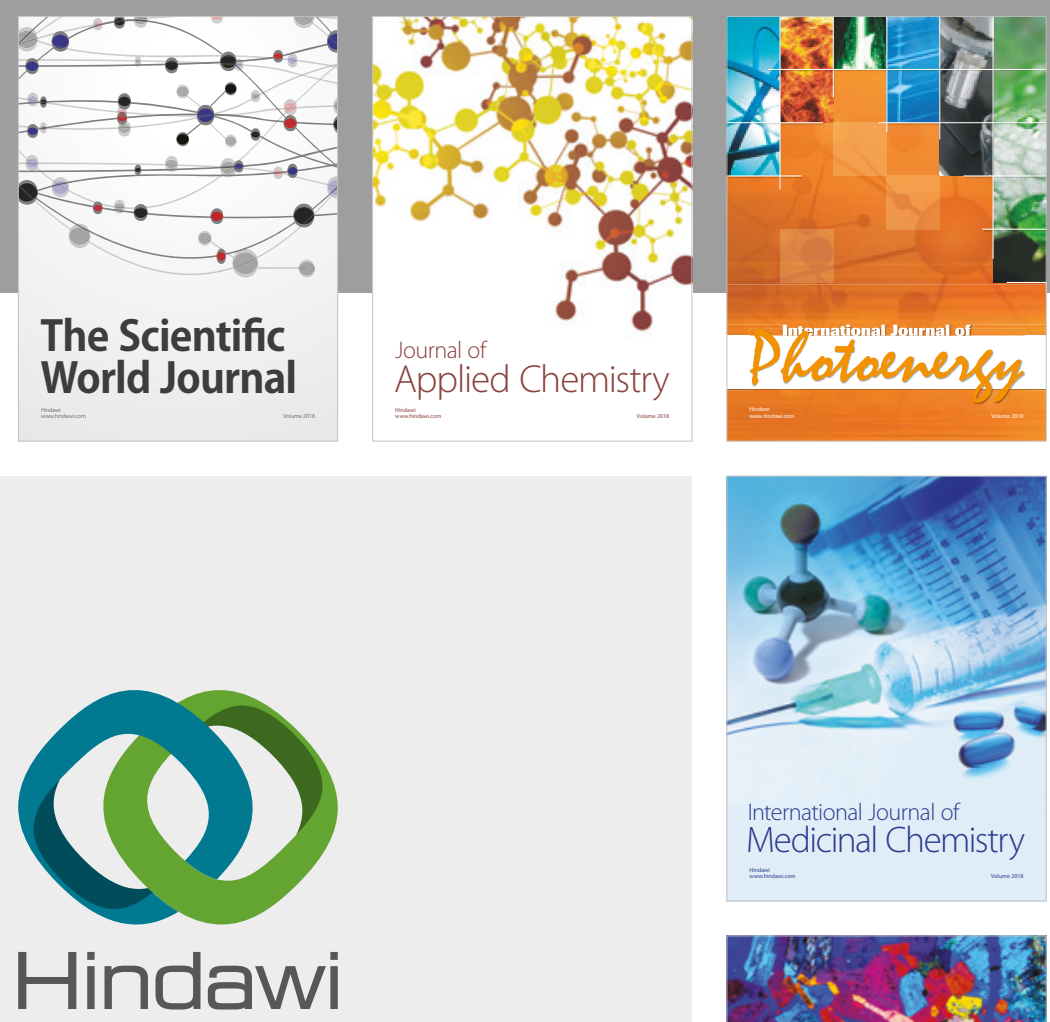

Submit your manuscripts at

www.hindawi.com
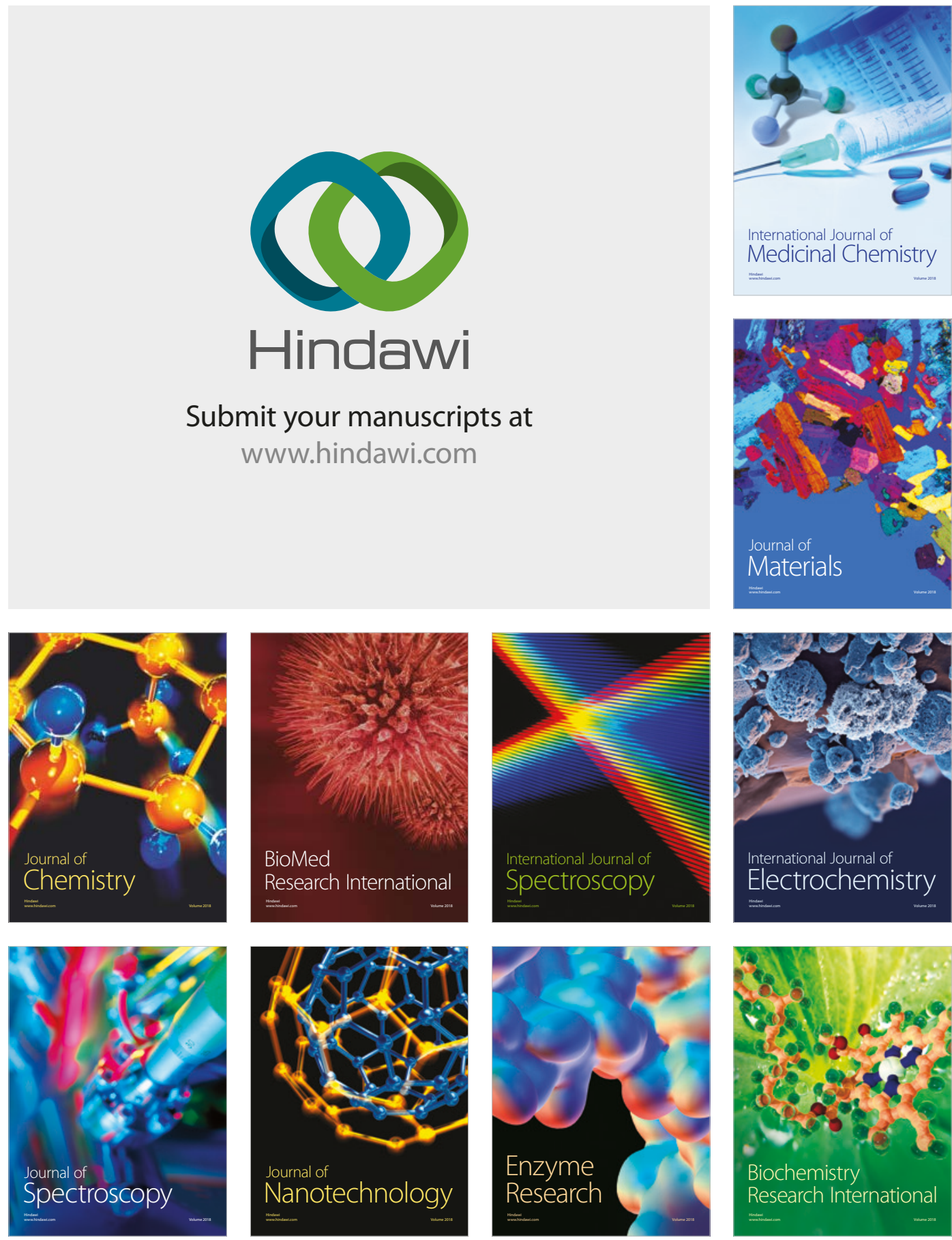
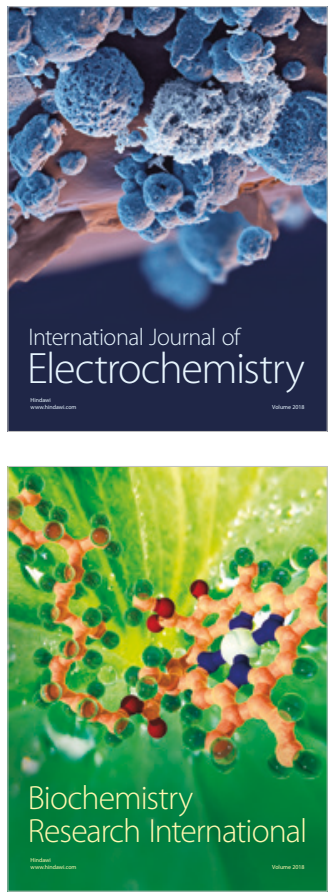